\title{
Alveolar epithelial cells undergo epithelial-mesenchymal transition in acute interstitial pneumonia: a case report
}

Hongbo $\mathrm{Li}^{1 \dagger}$, Jinjin Zhang ${ }^{2 \dagger}$, Xiaodong Song ${ }^{2}$, Tao Wang ${ }^{1}$, Zhi Li ${ }^{1}$, Dong Hao ${ }^{1}$, Xiaozhi Wang ${ }^{1}$, Qingyin Zheng ${ }^{3}$, Cuiping $\mathrm{MaO}^{2}$, Pan $\mathrm{Xu}^{2}$ and Changjun LV ${ }^{1 *}$

\begin{abstract}
Background: Acute interstitial pneumonia is a rare interstitial lung disease that rapidly progresses to respiratory failure or death. Several studies showed that myofibroblast plays an important role in the evolution of diffuse alveolar damage, which is the typical feature of acute interstitial pneumonia. However, no evidence exists whether alveolar epithelial cells are an additional source of myofibroblasts via epithelial-mesenchymal transition in acute interstitial pneumonia.

Case presentation: In this report, we present a case of acute interstitial pneumonia in a previously healthy 28-year-old non-smoking woman. Chest high-resolution computed tomography scan showed bilateral and diffusely ground-glass opacification. The biopsy was performed on the fifth day of her hospitalization, and results showed manifestation of acute exudative phase of diffuse alveolar damage characterized by hyaline membrane formation. On the basis of the preliminary diagnosis of acute interstitial pneumonia, high-dose glucocorticoid was used. However, this drug showed poor clinical response and could improve the patient's symptoms only during the early phase. The patient eventually died of respiratory dysfunction. Histological findings in autopsy were consistent with the late form of acute interstitial pneumonia.

Conclusions: The results in this study revealed that alveolar epithelial cells underwent epithelial-mesenchymal transition and may be an important origin of myofibroblasts in the progression of acute interstitial pneumonia. Conducting research on the transformation of alveolar epithelial cells into myofibroblasts in the lung tissue of patients with acute interstitial pneumonia may be beneficial for the treatment of this disease. However, to our knowledge, no research has been conducted on this topic.
\end{abstract}

Keywords: Acute interstitial pneumonia, Epithelial-mesenchymal transition, Myofibroblast

\section{Background}

Acute interstitial pneumonia (AIP), also known as Hamman-Rich syndrome, is a fulminating interstitial lung disease characterized by acute respiratory failure. The clinical features presented by majority of patients are described as a flulike prodrome including sore throat, headache, cough, dyspnea, and often fever with abrupt onset and short duration [1].

\footnotetext{
* Correspondence: songxd71@163.com

${ }^{\dagger}$ Equal contributors

${ }^{1}$ Department of Pulmonary medicine, Binzhou Medical University Hospital, Binzhou, P.R. China

Full list of author information is available at the end of the article
}

The histological hallmark of AIP was defined as diffuse alveolar damage (DAD), which is a nonspecific reaction in the lung to many injurious agents. The pathologic progress of $\mathrm{DAD}$ can be separated into three phases: acute exudative phase, which is characterized by interstitial edema, hyaline membrane, and acute interstitial inflammation accumulation [2]; proliferative phase, which is characterized by interstitial thickening and the appearance of granulation tissue in alveolar spaces [3]; and fibrotic phase, which is characterized by enlarged fibrotic septa and laminated intra-alveolar fibrosis [4].

The primary focus of therapy is supportive care. However, the use of glucocorticoids and immunosuppressive

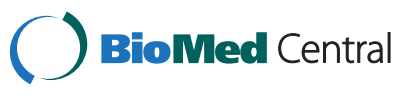

(c) 2014 Li et al.; licensee BioMed Central Ltd. This is an Open Access article distributed under the terms of the Creative Commons Attribution License (http://creativecommons.org/licenses/by/2.0), which permits unrestricted use, distribution, and reproduction in any medium, provided the original work is properly credited. The Creative Commons Public Domain Dedication waiver (http://creativecommons.org/publicdomain/zero/1.0/) applies to the data made available in this article unless otherwise stated. 
therapies is only effective in some cases. The casefatality ratio remains high ( $>60$ percent) despite intensive treatment and the majority of patients die within six months of presentation [5]. Thus, the pathologic process of the disease should be urgently explored, and a new therapeutic target should be identified.

Epithelial-mesenchymal transition (EMT), defined by the loss of epithelial characteristics and the acquisition of a mesenchymal phenotype, is essential for the progress of embryonic development [6]. Numerous studies revealed that the abnormal activation of EMT programs plays an important role in tissue fibrosis, cancer invasion, and metastasis [7-9]. However, the emergence and importance of EMT in lungs of patients with AIP remain unclear.

In this report, we present the case of a 28-year-old female diagnosed with AIP through histological and radiological lung examinations. Pathological and ultrastructural findings at open lung biopsy and autopsy showed that alveolar epithelial cells underwent EMT which may be beneficial for early intervention of AIP.

\section{Case presentation}

A previously healthy 28-year-old non-smoking woman was admitted to the hospital because of cough, mild dyspnoea, and fever of $38^{\circ} \mathrm{C}$. The blood pressure, heart rate, and respiration rate of the patient were $103.0 / 63.0 \mathrm{mmHg}$, 100 beats/min, and 25 beats/min, respectively. During physical examination, she presented tachycardia, cyanosis, and diffusely reduced breath sounds but no vesicular murmur, crackles, or wheezing. Blood gas analysis revealed the following findings: $\mathrm{pH} 7.47 ; \mathrm{pCO}_{2}, 40 \mathrm{mmHg} ; \mathrm{pO}_{2}$, $53 \mathrm{mmHg}$; $\mathrm{HCO}_{3}^{-}, 29.1 \mathrm{mmol} / \mathrm{L}$; and Lac, $0.6 \mathrm{mmol} / \mathrm{L}$. These findings indicate hypoxemia. High-resolution computed tomography (HRCT) of the chest revealed bilateral diffuse airspace opacification (Figure 1A). Levofloxacin was administered intravenously for $4 \mathrm{~d}$. Her condition deteriorated with acute onset of dyspnoea and rapidly progressive respiratory failure, and the patient required intubation and mechanical ventilation. Blood gas analysis indicated hypoxemia; $\mathrm{pH} 7.19 ; \mathrm{pO}_{2}, 32 \mathrm{mmHg}$; and $\mathrm{pCO}_{2}$, $35 \mathrm{mmHg}$. HRCT revealed the deterioration of diffuse ground-glass opacification (Figure 1B). Fiberoptic bronchoscopy was performed on the same day after the patient was transferred to an intensive care unit. The bronchial tubes were normal with little sputum. Microbiologic investigations were negative. Transbronchial lung biopsies were performed on the same lobe (left upper lobe) on the fifth day of hospitalization. The first lung specimen exhibited edema, hyaline membrane formation, and acute interstitial inflammation, which all suggest an exudative phase of AIP (Figure 2A). High doses of intravenous methylprednisolone (500 mg for $3 \mathrm{~d}$ and $160 \mathrm{mg}$ for $2 \mathrm{~d}$ ) were administered based on presumptive diagnosis of interstitial lung disease. After $5 \mathrm{~d}$, HRCT revealed diffuse ground-glass attenuation (Figure $1 C$ ). However, the patient still had acute hypoxic respiratory failure and could not be extubated after the procedure. Despite initiating intravenous with normal dose of methylprednisolone ( $80 \mathrm{mg}$ per day) and high concentrations of oxygen, the patient remained intubated for eight weeks. Chest X-ray analysis indicated that her lung deteriorated did not improve even when highdose glucocorticoid was re-administered. Her oxygen saturation was only $30 \%$ when the fraction of inspired oxygen was $100 \%$. The patient eventually expired after $62 \mathrm{~d}$ of hospitalization. The patient underwent autopsy, and the slides showed diffusely thickened alveolar septal interstitium by hyaline membrane remnants, pulmonary interstitial and alveolar edema, type II pneumocyte hyperplasia (Figure 2B), and significant amount of myofibroblasts (Figure 3). These results indicate organized DAD. Transmission electron microscopy revealed that the epithelial cells, which are characterized by their basement membrane

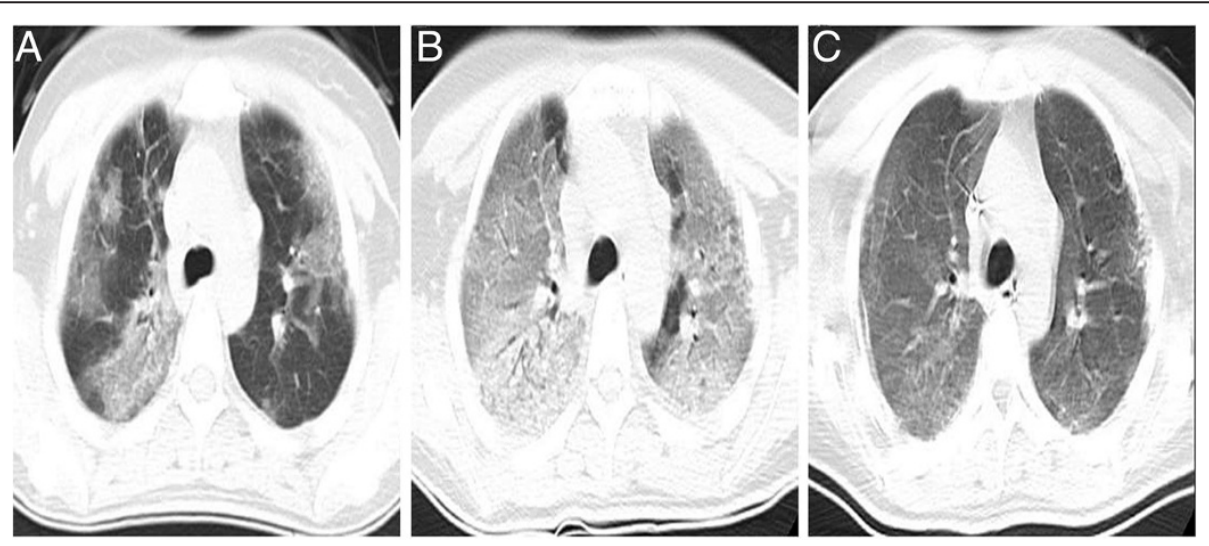

Figure 1 Radiological findings of the patient. A, Chest High-resolution computed tomography (HRCT) showed bilateral diffuse airspace opacification when the patient was hospitalized; B, Chest HRCT, taken on the fourth hospital day, demonstrated the worsening of diffused ground-glass opacification. $\mathbf{C}$, the HRCT findings of the patient, who was treated with high dose of methylprednisolone for $5 \mathrm{~d}$, showed diffuse ground-glass attenuation. 


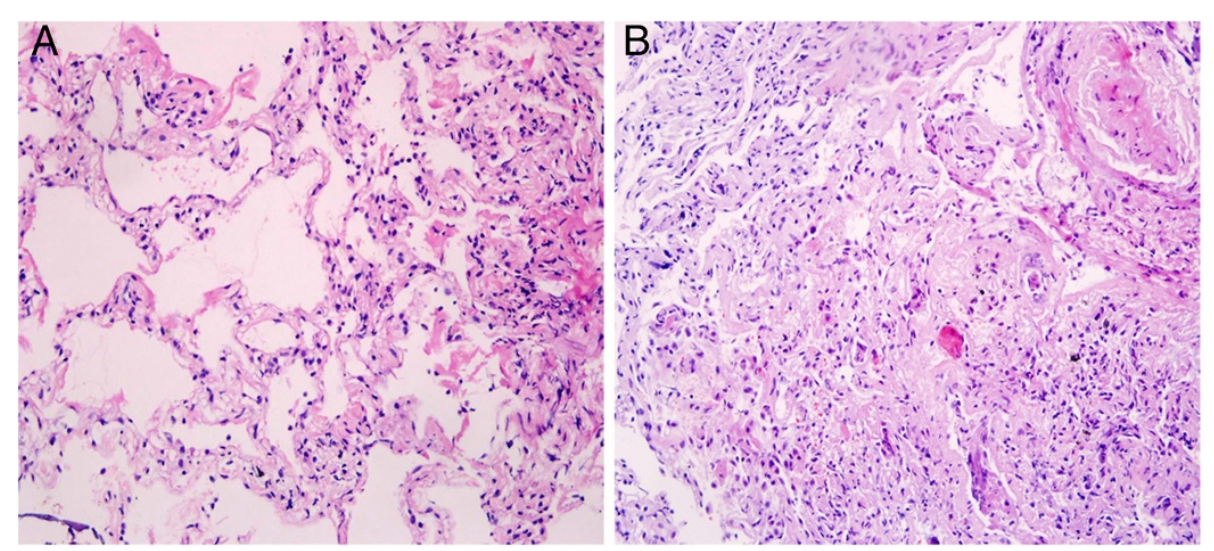

Figure 2 Hematoxylin and eosin (H \& E) stain. A, Lung biopsy revealed edema, hyaline membranes, and acute interstitial inflammation representing the exudative phase of DAD. B, Lung autopsy showed interstitial and intra-alveolar fibroblast proliferation, which is the feature of the fibrotic phase.

and specialized cell-cell junction structures, contained bundles of filament in the cytoplasm (Figure 4). The presence of filaments in these cells suggested the occurrence of EMT. We then determined the changes in EMT-related proteins, such as surfactant associated protein (SPC), $\alpha$-smooth muscle actin ( $\alpha$-SMA), and Snail. (Santa Cruz Biotechnology Inc. Dallas, Texas, USA). The results of the double immunostaining of the lungs showed mesenchymal specific protein $\alpha$-SMA in the alveolar epithelial cells (SPC-positive cells). The double positive cells were evidently increased in the lung tissue from the $62 \mathrm{~d}$ autopsy compared with that from the $5 \mathrm{~d}$ biopsy (Figure 5). The zinc finger transcription factor
Snail was evidently expressed in the lung tissue, especially in the lung tissue from the $62 \mathrm{~d}$ autopsy (Figure 6).

\section{Conclusions}

AIP is one of the six subtypes of major idiopathic interstitial pneumonia according to the American Thoracic Society/European Respiratory Society classification [10]. Given that many diseases could mimic AIP, multidisciplinary diagnosis, which requires a combination of clinical, radiological, and pathological findings, is needed. The case reported a patient with typical appearances of AIP. Apart from supplemental oxygen and mechanical ventilation, the patient received high-dose intravenous

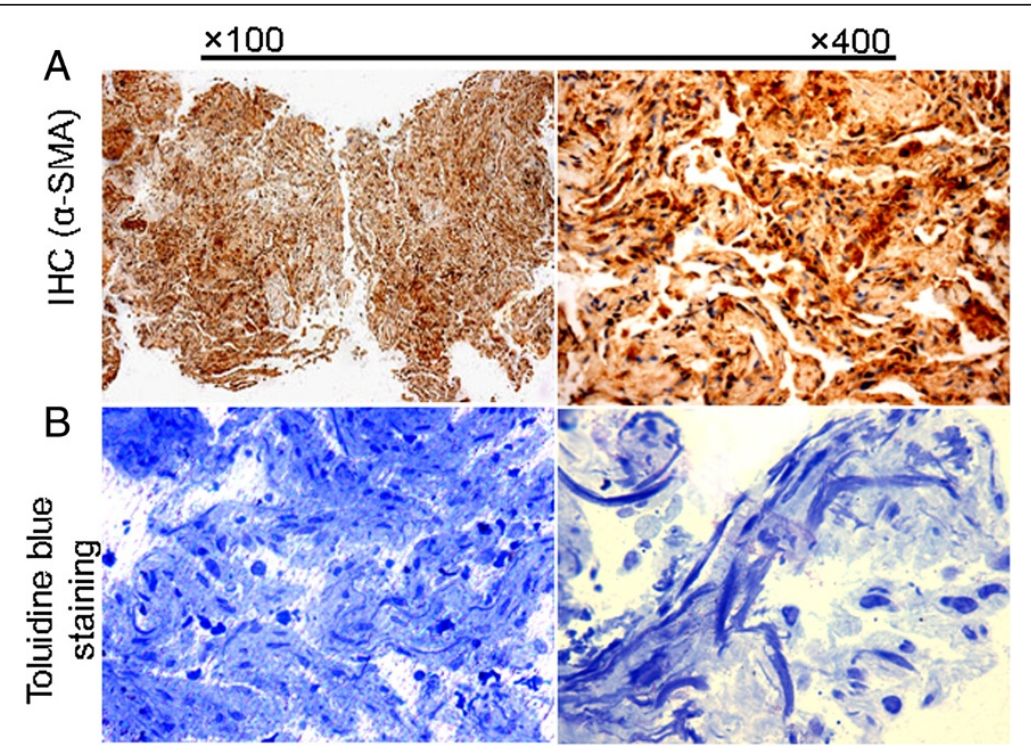

Figure 3 Emergence of myofibroblasts in lung tissue. A, Immunohistochemistry staining showed that an amount of a-SMA-positive cells existed in the lung section from autopsy (62 d). B, Toluidine blue staining demonstrated a significant amount of fibroblastic foci in the lung section from autopsy (62 d). 


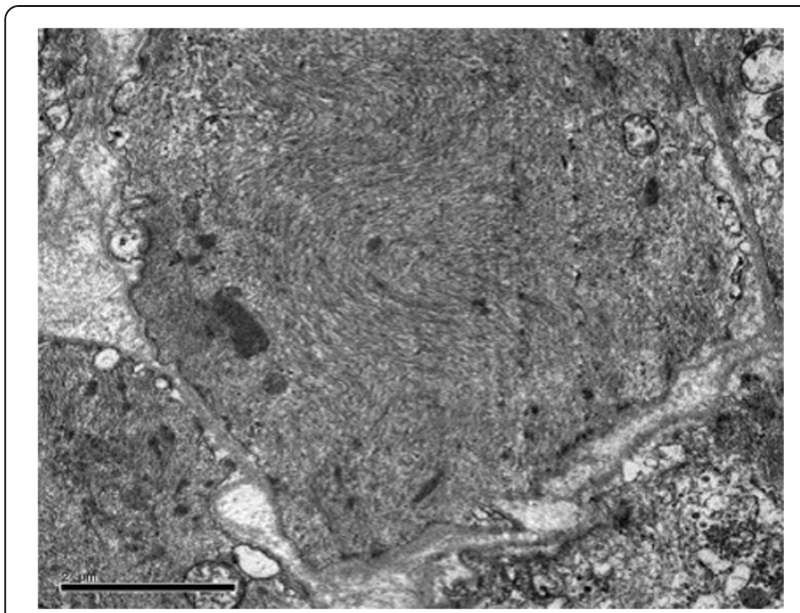

Figure 4 Ultrastructural findings of the lung tissue from the patient. Ultrastructural finding on autopsy ( $62 \mathrm{~d}$ ) of the lung revealed bundles of actin microfilaments in the epithelial cells characterized partly by basement membrane.

methylprednisolone for $5 \mathrm{~d}$ and normal dose of methylprednisolone for several days. However, the treatment could not contribute to the patient's survival. The data from this case confirmed the occurrence of EMT in AIP and maybe beneficial for the treatment of this disease.
The process of lung injury with subsequent development of scar tissue in idiopathic pulmonary fibrosis has been likened to an abnormal wound healing model. A similar construct may be applied to AIP [11]. In theory, intervention before the deposition of mature collagen should allow the restoration of normal lung architecture. The marked expansion of myofibroblast numbers within the alveolar septa responds for the subsequent collagen production in the proliferative and fibrotic AIP [12]. Consistent with this conclusion, we also detected an amount of myofibroblast in the patient's lung tissue. This myofibroblast may be related to the AIP process.

Previous observations revealed that injured epithelial cells could gradually lose their epithelial cell markers and polarity, thus expressing mesenchymal markers and acquiring single-cell motility [13], which was defined as EMT. During EMT, cytoskeletal reprogramming establishes the presence of $\alpha$-SMA stress fibers in epithelial cells [14]. Through this transition, alveolar epithelial cells serve as an importance source of myofibroblasts during tissue injury response. Kalluri et al. [15] reported that under inflammatory stress, $30 \%$ of myofibroblasts can arise via EMT, whereas resident fibroblasts contribute only $23 \%$ in the kidney. Several articles reported that

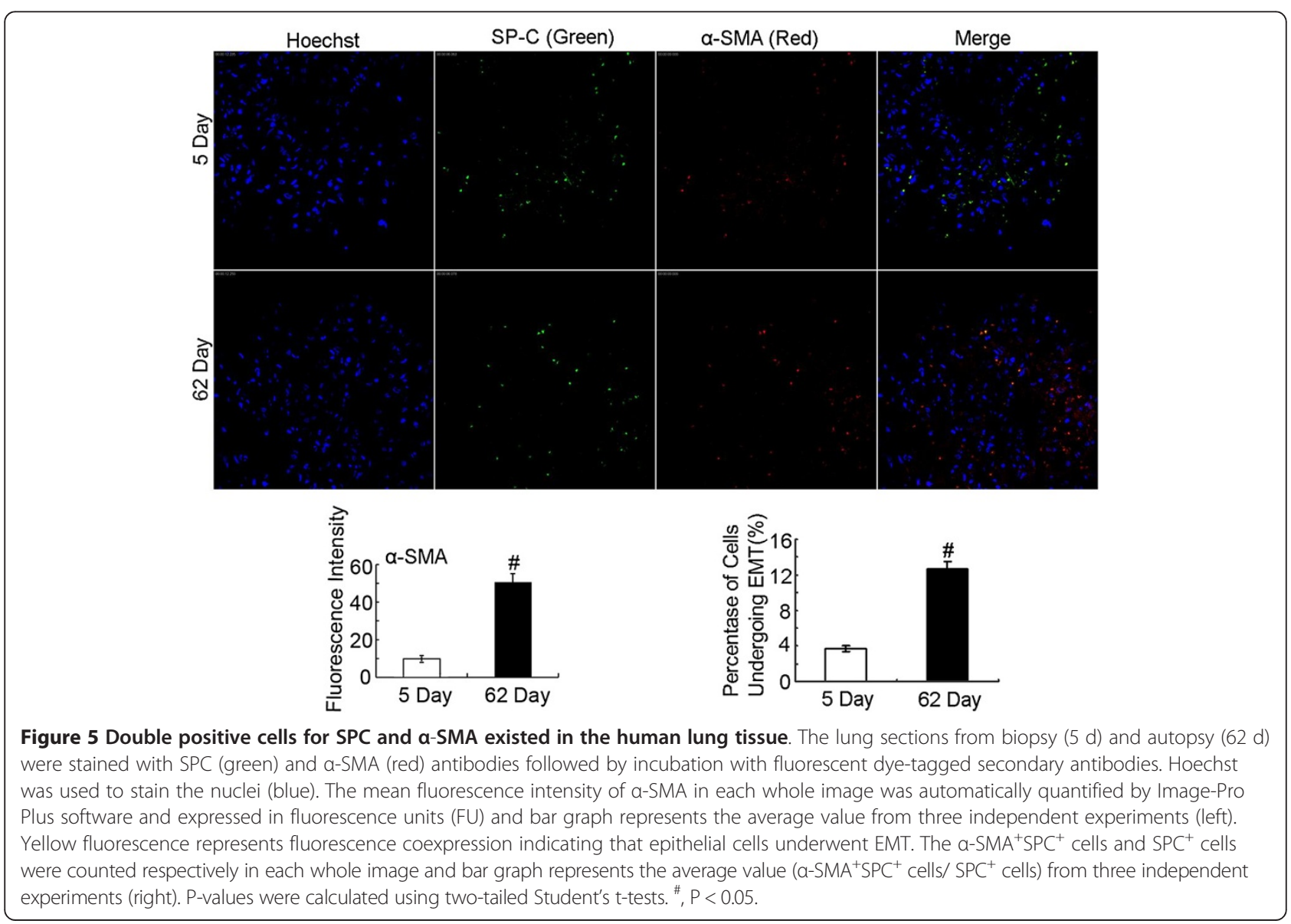




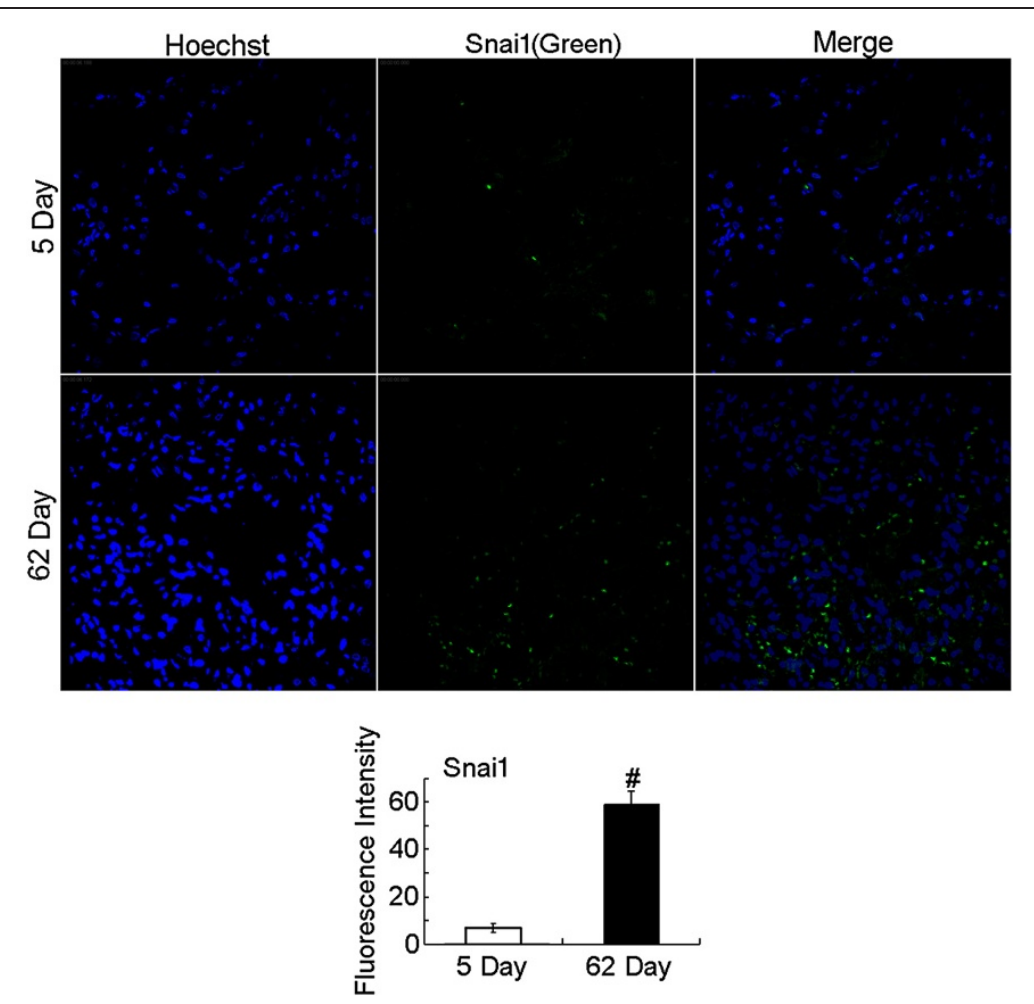

Figure 6 Detection of Snai1 expression in human lung tissue. The EMT transcription factor was detected by confocal immunofluorescence microscopy. The mean fluorescence intensity of Snai1 in each whole image was automatically quantified by Image-Pro Plus software and expressed in fluorescence units (FU). Bar graph represents the average value from three independent experiments. Increased expression of Snai1 (green) was observed in the lung sections from biopsy (5 d) and autopsy (62 d). P-values were calculated using two-tailed Student's t-tests. ${ }^{\#}, \mathrm{P}<0.01$.

EMT may participate in various lung diseases, such as developmental disorders, fibrotic tissue remodeling, and lung cancer in humans [16-18]. Harada et al. [19] demonstrated the presence of EMT in patients with usual interstitial pneumonia pattern. However, Yamada et al. [20] obtained conflicting results and did not detect double-positive cells for E-cadherin, ICAM-1, LEA CD44v9, SP-A, $\alpha-$ SMA, or vimentin in lung tissues from patients with idiopathic pulmonary fibrosis and nonspecific interstitial pneumonia. Therefore, the evidence of myofibroblasts originating from epithelial cells through EMT in interstitial pneumonia remains controversial. Our ultrastructural data supported the existence of EMT in the lung tissue of patients with AIP. We also found that SPC and $\alpha-S M A$, which are markers for alveolar epithelial cells and myofibroblasts, respectively [16], coexisted in the patient's sections. The EMT program in epithelial cells is identified to be switched on by many transcription factors. For example, Snail, a major transcription factor governing EMT [21], could regulate the expression of genes related to epithelial and mesenchymal phenotype [22]. We found that the expression of Snail in the lung tissue of the patient was upregulated in the proliferative phase of AIP compared with the exudative phase of AIP.
In conclusion, the results of this study confirmed that alveolar epithelial cells underwent EMT, which maybe an important origin of myofibroblasts in the progression of AIP. Although pathological manifestation may vary from one case of AIP to another, our finding partly indicated the possibility and importance of EMT in AIP and provided a potential therapeutic method of preventing EMT in AIP.

\section{Consent}

Written informed consent was obtained from the lung of the patient for publication of this Case Report and any accompanying images. A copy of the written consent is available for review by the Editor-in-Chief of this journal form.

\section{Abbreviations}

AIP: Acute interstitial pneumonia; EMT: Epithelial-mesenchymal transition; HRCT: High-resolution computed tomography; DAD: Diffuse alveolar damage; SPC: Surfactant associated protein; a-SMA: a-Smooth muscle actin.

\section{Competing interests}

The authors declare that they have no competing interests.

\section{Authors' contributions}

$\mathrm{HL}$ and JZ analyzed, interpreted the patient's data and drafted the manuscript. XS performed the ultrastructural study and analysis. TW and ZL 
examined the patient and contributed to manuscript preparation. DH and XW contributed to discussions about the patient. CM performed immunohistochemical analysis. QZ and CL revised the pathology data and supervised the case report. All authors read and approved the final manuscript.

\section{Acknowledgments}

This study was supported by Taishan Scholar Project to Fang Han and National Natural Science Foundation of China (NO. 81273957, NO.31300288), Important Project of Science and Technology of Shandong Province (NO.2010GWZ20254, NO. 2011GHY11501), Natural Science Foundation of Shandong Province (NO.ZR2009EM006, ZR2012HQ042), Project of Science and Technology of Education Department of Shandong Province (NO.J11FL87).

\section{Author details}

'Department of Pulmonary medicine, Binzhou Medical University Hospital, Binzhou, P.R. China. ${ }^{2}$ Medicine Research Center, Binzhou Medical University, Yantai, P.R. China. ${ }^{3}$ Department of Otololaryngology, Case Western Reserve University, Cleveland, OH, USA.

Received: 4 November 2013 Accepted: 9 April 2014

Published: 23 April 2014

\section{References}

1. American Thoracic Society, European Respiratory Society.American Thoracic Society/European Respiratory Society international Multidisciplinary Consensus Classification of the Idiopathic Interstitial Pneumonias: This joint statement of the American Thoracic Society (ATS) and the European Respiratory Society (ERS) was adopted by the ATS board of directors. June 2001 and by the ERS Executive Committee. June 2001. Am J Respir Crit Care Med 2002, 165:277-304.

2. Suh GY, Kang EH, Chung MP, Lee KS, Han J, Kitaichi M, Kwon OJ: Early intervention can improve clinical outcome of acute interstitial pneumonia. Chest 2006, 129:753-761.

3. Mukhopadhyay S, Parambil JG: Acute interstitial pneumonia (AIP): relationship to Hamman-Rich syndrome, diffuse alveolar damage (DAD), and acute respiratory distress syndrome (ARDS). Semin Respir Crit Care Med 2012, 33:476-485.

4. Katzenstein AL, Bloor CM, Leibow AA: Diffuse alveolar damage: the role of oxygen, shock, and related factors.A review. Am J Pathol 1976, 85:209-228.

5. Quefatieh A, Stone CH, DiGiovine B, Toews GB, Hyzy RC: Low hospital mortality in patients with acute interstitial pneumonia. Chest 2003, 124:554-559.

6. Flier SN, Tanjore H, Kokkotou EG, Sugimoto H, Zeisberg M, Kalluri R: Identification of epithelial to mesenchymal transition as a novel source of fibroblasts in intestinal fibrosis. J Biol Chem 2010, 285:20202-20212.

7. Acloque H, Adams MS, Fishwick K, Bronner-Fraser M, Nieto MA: Epithelial-mesenchymal transitions: the importance of changing cell state indevelopment and disease. J Clin Invest 2009, 119:1438-1449.

8. Selman M, Pardo A, Kaminski N: Idiopathic pulmonary fibrosis: aberrant recapitulation of developmental programs? PLoS Med 2008, 5:e62.

9. Yilmaz M, Christofori G: EMT, the cytoskeleton, and cancer cell invasion. Cancer Metastasis Rev 2009, 28:15-33.

10. Travis WD, Costabel U, Hansell DM, King TE Jr, Lynch DA, Nicholson AG, Ryerson CJ, Ryu JH, Selman M, Wells AU, Behr J, Bouros D, Brown KK, Colby TV, Collard HR, Cordeiro CR, Cottin V, Crestani B, Drent M, Dudden RF, Egan J, Flaherty K, Hogaboam C, Inoue Y, Johkoh T, Kim DS, Kitaichi M, Loyd J, Martinez FJ, Myers J, et al: An official American Thoracic Society/European Respiratory Society statement: update of the international multidisciplinary classification of the idiopathic interstitial pneumonias. Am J Respir Crit Care Med 2013, 188:733-748.

11. Pache JC, Christakos PG, Gannon DE, Mitchell JJ, Low RB, Leslie KO: Myofibroblasts in diffuse alveolar damage of the lung. Mod Pathol 1998, 11:1064-1070

12. Vourlekis JS, Brown KK, Schwarz MI: Acute Interstitial Pneumonitis: current understanding regarding diagnosis, pathogenesis, and natural history. Semin Respir Crit Care Med 2001, 22:399-408.

13. Willis BC, Liebler JM, Luby-Phelps K, Nicholson AG, Crandall ED, du Bois RM, Borok Z: Induction of epithelial-mesenchymal transition in alveolar epithelial cells by transforming growth factor-beta1: potential role in idiopathic pulmonary fibrosis. Am J Pathol 2005, 166:1321-1332.

14. Buckley ST, Medina C, Davies AM, Ehrhardt C: Cytoskeletal re-arrangement in TGF- $\beta 1$-induced alveolar epithelial-mesenchymal transition studied by atomic force microscopy and high-content analysis. Nanomedicine 2012, 8:355-364.

15. Kalluri $R$, Weinberg RA: The basics of epithelial-mesenchymal transition. J Clin Invest 2009, 119:1420-1428.

16. Bartis D, Mise N, Mahida RY, Eickelberg O, Thickett DR: Epithelial-mesenchymal transition in lung development and disease: does it exist and is it important? Thorax, in press.

17. Wang M, Zhang J, Song X, Liu W, Zhang L, Wang X, Lv C: Astaxanthin ameliorates lung fibrosis both in vivo and in vitro through preventing transdifferentiation, inhibiting proliferation and promoting apoptosis of activated cells. Food Chem Toxicol 2013, 56:450-458.

18. Song X, Liu W, Xie S, Wang M, Cao G, Mao C, Lv C: All-transretinoic acid ameliorates bleomycin-induced lung fibrosis by downregulating the TGF- $\beta 1 /$ Smad3 signaling pathway in rats. Lab Invest 2013, 3:1219-1231.

19. Harada T, Nabeshima K, Hamasaki M, Uesugi N, Watanabe K, Iwasaki H: Epithelial-mesenchymal transition in human lungs with usual interstitial pneumonia: quantitative immunohistochemistry. Pathol Int 2010, 60:14-21.

20. Yamada M, Kuwano K, Maeyama T, Hamada N, Yoshimi M, Nakanishi Y, Kasper M: Dual-immunohistochemistry provides little evidence for epithelial-mesenchymal transition in pulmonary fibrosis. Histochem Cell Biol 2008, 129:453-462.

21. Nagarajan D, Melo T, Deng Z, Almeida C, Zhao W: ERK/GSK3ß/Snail signaling mediates radiation-induced alveolar epithelial-to-mesenchymal transition. Free Radic Biol Med 2012, 52:983-992.

22. Jayachandran A, Königshoff M, Yu H, Rupniewska E, Hecker M, Klepetko W, Seeger W, Eickelberg O: SNAI transcription factors mediate epithelial-mesenchymal transition in lung fibrosis. Thorax 2009, 64:1053-1061

doi:10.1186/1471-2466-14-67

Cite this article as: Li et al:: Alveolar epithelial cells undergo epithelial-mesenchymal transition in acute interstitial pneumonia: a case report. BMC Pulmonary Medicine 2014 14:67.

\section{Submit your next manuscript to BioMed Central and take full advantage of:}

- Convenient online submission

- Thorough peer review

- No space constraints or color figure charges

- Immediate publication on acceptance

- Inclusion in PubMed, CAS, Scopus and Google Scholar

- Research which is freely available for redistribution

Submit your manuscript at www.biomedcentral.com/submit
C BioMed Central 